\title{
REESCRIBIR EL VÉRTIGO (DE ENTRE LOS VIVOS): LA IMPRONTA CINEMATOGRÁFICA DE HITCHCOCK EN ASÍ EMPIEZA LO MALO, DE JAVIER MARÍAS
}

\author{
REWRINTING VERTIGO (AMONG THE LIVING): \\ THE CINEMATOGRAPHIC TRACES OF HITCHCOCK \\ IN ASÍ EMPIEZA LO MALO BY JAVIER MARÍAS
}

\author{
Carmen María LÓPEZ LÓPEZ \\ Universidad de Murcia \\ carmenmaria.lopez14@um.es
}

Resumen: En este estudio se propone analizar la impronta cinematográfica de Vértigo (De entre los muertos) (1958), de Alfred Hitchcock, en Así empieza lo malo de Javier Marías (2014). Desde una perspectiva semiótica, resulta esencial focalizar nuestra atención en el concepto de transducción de mundos ficcionales (Dolezel, 1999), con el objetivo de establecer los vínculos entre la obra literaria y la producción cinematográfica. Para este propósito, este artículo ofrece un análisis de las principales conexiones entre las dos producciones artísticas (la búsqueda de un detective, el espionaje, la imitación de vidas, los personajes femeninos, el drama policíaco o el humor).

Palabras clave: Transducción. Semiótica. Reescritura. Alfred Hitchcock. Vértigo (De entre los muertos). Javier Marías. Así empieza lo malo.

Abstract: This study intends to analyze the cinematographic traces of Vértigo (De entre los muertos) (1958), by Alfred Hitchcock, on Javier Marías's Así empieza lo malo (2014). From a semiotic perspective, it is essential to focus our attention on the concept of transduction of fictional worlds (Dolezel, 1999), with the aim of establishing the links between the literary work and the film. To this purpose, this paper offers an analysis of the main connections between both artistic productions (the search for a detective, the espionage, the imitation of lifes, the women's characters, the police drama and the humour).

Key Words: Transduction. Semiotic. Rewriting. Alfred Hitchcock. Vértigo (Among the Living) Javier Marías. Así empieza lo malo. 


\section{PRELIMINAR}

Desde que el séptimo arte adquiriera carta de naturaleza en las décadas iniciales del pasado siglo, la novela se ha nutrido de las inmensas posibilidades que los imaginarios filmicos ofrecen para el acto de crear ficciones. El cine - la máquina fabuladora de imágenes - se alza como dispositivo poderoso en el universo de Javier Marías, donde a partir de sus ensayos sobre cine (Marías, 2005) es posible rastrear el gusto del escritor por la filmografía de Hitchcock, a la par con las propias referencias explícitas a Vértigo y a otras obras hitchcockianas presentes en Así empieza lo malo y en otras de sus novelas (Herzberger, 2011: 22). Si ya el germen narrativo de la que fue su primera novela (Los dominios del lobo, 1971) se encuentra en las "ochenta y cinco películas norteamericanas consumidas por Marías durante una breve estancia en París" (Steenmeijer, 2001: 7), el propio escritor reconoce la influencia en sus obras de alguna escena o pasaje "contemplado en la oscuridad de una sala" (Marías, 2005: 30). Según las encuestas que la revista Nickel Odeon realizó al escritor (2005: 273-281), entre sus filmes predilectos figuran Con la muerte en los talones ${ }^{1}$, Encadenados ${ }^{2}$, Extraños en un tren ${ }^{3}$, Testigo de cargo ${ }^{4}$ o La ventana indiscreta 5 .

A partir de la influencia de Hitchcock reconocida por el escritor, así como de las referencias explícitas que convocan directamente los filmes del director británico, es posible concebir reescrituras de los imaginarios filmicos en el proyecto narrativo de Javier Marías. Se propone, pues, una superación del concepto de adaptación, en virtud de apreciar reescrituras mucho más complejas en las que un autor proyecta en su universo subjetivo irradiaciones de otras obras en las que se halla inmerso (Pérez Bowie, 2010: 27), donde las similitudes y puntos de intersección en la configuración ficcional aparecen velados.

1 Según se registra en Nickel Odeon (n. ${ }^{\circ}$, otoño de 1997), Con la muerte en los talones es para Marías una de las diez mejores películas de la historia del cine. La significación de este filme se extiende a la configuración ficcional de Así empieza lo malo, donde es mencionado explícitamente y muchos de los capítulos de espionaje y persecución a un ritmo vertiginoso evocan la persecución a Cary Grant de la avioneta, con cierta inspiración en las escenas persecutorias en el Monte Rushmore.

2 Para Javier Marías (2005: 273), es una de las diez películas románticas más relevantes de la historia del cine (Nickel Odeon, n. ${ }^{2}$, primavera de 1996).

3 Recogida en Nickel Odeon (n. ${ }^{\circ} 33$, invierno de 2003) como una de las películas más memorables sobre cine y deporte.

4 Mencionada a propósito de Marlene Dietrich, quien para Marías es una de las mejores actrices que el cine ha filmado con un cigarrillo.

5 El memorable filme La ventana indiscreta figura como una de las veinticinco películas de nuestra vida, tal como recogió Almudena Lería (coord.), en Las 25 películas de nuestra vida (Encuesta entre 100 cinéfilos españoles), Madrid, Nickel Odeón. 
¿Dónde buscar entonces los indicios de reescritura que permitan articular la transducción? Desde el prisma de la transducción de los mundos ficcionales (Dolezel, 1999: 315), ha de haber una o varias pruebas textuales entre la proto-obra (Vértigo, 1958) y la reescritura (Así empieza lo malo, 2014). Estos indicios textuales marcan la conexión entre dos obras pertenecientes a tradiciones culturales distintas (Estados Unidos-España), presentadas sobre la base de diferentes códigos semióticos (verbal-icónico). En el caso de las obras que nos ocupan, si bien no encontramos pruebas textuales en los títulos de la novela y el filme, sí existen otras marcas que, según Dolezel (1999: 315), evidencian la similitud entre dos mundos ficcionales: citas y alusiones intertextuales (Vértigo y otras obras que componen la filmografía de Hitchcock se mencionan en la novela de manera explícita), una homología entre las constelaciones de agentes (marido, detective, la mujer y su doble), paralelismo entre las tramas (encargo de espionaje, persecución y muerte final del personaje femenino) y semejanza en sus escenarios (reminiscencia en el santuario de Darmstadt de las atmósferas hitchcockianas).

Una vuelta de tuerca al desafío de los procedimientos transductivos opera cuando ya no se trata de traducir al lenguaje (mediante palabras) los acontecimientos vividos, sino cuando hay que indagar en la ósmosis entre distintos lenguajes o códigos semióticos que, a propósito del "sistema de modelización secundario" (Lotman, 1978: 34), se alzan sobre la base de la lengua natural. Este hecho concierne de manera prioritaria a este estudio, a partir de unas líneas de fuerza que vinculan Vértigo (1958) de Alfred Hitchcock y Así empieza lo malo (2014) de Javier Marías. De este modo, se pone de relieve que "el texto literario y el texto audiovisual son de naturaleza semiótica totalmente distinta y su trasvase de uno a otro medio expresivo ha comportado necesariamente un proceso creativo de transubstanciación" (Gubern, 2013: 9).

Tras haber introducido uno de los principales desafíos que concierne a los estudios comparatistas, es preciso apuntar el modo de proceder en este análisis interdiscursivo. En concreto, el marco metodológico que se seguirá es el propio de la Tematología (Guillén, 1985) como vertiente fecunda de la Literatura Comparada. Se va a adoptar, por tanto, como punto de partida la idea de transducción de mundos narrativos (Piñera Tarque, 2009: 46), desde una perspectiva de análisis tematológico, lo que no excluye el tratamiento de otros aspectos de carácter estético, mítico o simbólico que puedan enriquecer esta cala hermenéutica. 


\section{LAZOS ARGUMENTALES Y SIMILITUD EN LOS PERSONAJES}

Trazar los ejes que vinculan producciones estéticas tan dispares como una novela y un filme es siempre un ejercicio intelectual incardinado en un proceso semiótico fascinante y enriquecedor. Si bien se han apuntado los escollos sobre la imposible transducción exacta entre lenguajes artísticos, esta disparidad no impide dibujar sus homologías, es decir, ahondar en la narratividad del cine y en la visualidad (substrato cinematográfico) de la novela. Lo valioso de este modo de proceder es que se prioriza la búsqueda de los matices y contrastes, los cambios y sus motivaciones, más allá de la reproducción fidedigna y exacta de un particular universo ficticio.

El asedio de las relaciones entre Vértigo y Así empieza lo malo implica una triple puesta en abismo, por cuanto ya la obra de Hitchcock se basa en una obra francesa, como primer despliegue transductivo, que será seguido por las analogías temáticas, estructurales y simbólicas del filme de Hitchcock y la novela de Marías. La historia de Vértigo (1958) tiene como punto de partida la obra Sueurs Froides (D'entre Les Morts) (1954), de los autores franceses Pierre Boileau y Thomas Narcejac. Si bien Hitchcock quiso comprar los derechos de una de sus novelas, Celle qui n'était plus, 1952), a ello se adelantó Henri-George Clouzot en Las diabólicas (Les diaboliques, 1955), por lo que —ante la fascinación mostrada por Hitchcock hacia el esquema de la narrativa criminal—, Boileau y Narcejac escribieron ad hoc cuatro o cinco novelas muy del gusto del maestro inglés (Sanabria, 2013: 71).

Sin embargo, en el filme de Hitchcock se ofrece un tratamiento distinto de algunas líneas argumentales de la novela francesa de Pierre Boileau y Thomas Narcejac, pero sin abandonar la idea central: el ex-policía al que un antiguo compañero le encarga seguir a su esposa, de la cual se terminará enamorando, "aunque su pérdida hace tambalear la frágil emocionalidad que se acentúa a raíz del posterior reencuentro con una mujer idéntica" (Sanabria, 2013: 72). Por lo tanto, una diferencia capital entre la novela francesa y la película de Hitchcock es que el sustrato grecolatino queda patente en la novela de los autores franceses, con la mención explícita a los mitos de Orfeo y Pigmalión, con el descensus ad inferos del héroe en La Eneida (2013: 73).

Este decir explícito se disuelve y se evoca de forma sugerente en la película de Hitchcock, que se alza como epítome del amor romántico ${ }^{6}$. De este modo, los complejos

6 "Es evidente que, más allá de las a menudo afortunadas conexiones establecidas entre VÉRTIGO y determinados mitos clásicos -Orfeo y Eurídice- o leyendas medievales -Tristán e lseo- e incluso más allá de las posibles vinculaciones con textos señeros de la literatura romántica- el ya citado El hombre de la arena, pero también EIMonje de Lewis, Lamia de Keats o El Retrato Oval de Poe-, determinados significantes puestos en funcionamiento por la enunciación remiten de manera más o menos directa a formulaciones estéticas del movimiento romántico" (Castro de Paz, 1992: 48). 
míticos "se desgranan con toda naturalidad en el puro fluir argumental de las imágenes" (Trías, 1998: 94). La fuerza arrolladora del filme de Hitchcock estriba más que en mostrar, en sugerir esos grandes temas universales que forman parte del imaginario del ser humano como una semilla inmortal (Balló y Pérez, 1997). Por su parte, la novela de Marías se orienta del lado de la evocación, en una línea de fuerza semejante a Hitchcock. Marías no presenta de un modo explícito ese descensus ad inferos del personaje, si bien al término de la novela se aprecia esa caída desbordante con la muerte de Beatriz Noguera y la perpetuidad en su hija, con la que se casará el espía Juan de Vere.

En lo concerniente a los puntos de intersección entre el filme y la novela, es preciso aludir a la vinculación que existe entre los grandes temas en el cine de Hitchcock y las obsesiones temáticas y argumentales propias de la narrativa de Marías. Cineasta y novelista convergen en el tratamiento del espionaje, el amor y su pulsión de muerte, el hilo de continuidad entre los vivos y los muertos ${ }^{7}$, o el secreto profundo (inconfesable) bajo el que subyace la verdad. De manera concreta, un motivo universal de gran simbolismo se cifra en el fracaso en la búsqueda de la amada, el descenso de Orfeo al inframundo, el viaje de Eneas como topos que se identifica con el infierno, si bien en el siglo XX se actualiza al poeta latino "desde la decadencia que caracteriza la estética negra antes que policíaca" (Sanabria, 2013: 76).

En Vértigo se da "el amor obsesivo y pasional que se enquista y llega hasta la muerte" (Jiménez Pascual, 2011: 193). El viaje de Juan de Vere y el de Scottie avanza en sentido regresivo, no hacia el futuro sino hacia el pasado, para indagar en la añoranza de lo que no fue y las consecuencias futuras de los actos. He aquí el verdadero germen mítico que vincula los esquemas narrativos de Marías y Hitchcock con la tradición órfica, con ese volver la mirada hacia atrás sin poder resistir la tentación: "Scottie quiere como Orfeo, rescatar a Eurídice del infierno, sólo que, al igual que el personaje mítica griego, no resiste la tentación de mirar atrás, o de abrir las puertas del pasado" (Trías, 1998: 32).

Centrándonos ahora en las similitudes entre los personajes, se puede apreciar un esquema análogo en su concepción: marido insatisfecho con su relación amorosa (Gavin Elster-Eduardo Muriel) busca a un detective (Scottie-Juan de Vere) para que espíe los pasos de su mujer (Madeleine-Beatriz Noguera). Las consecuencias de este acto resultan inesperadas y conducen la trama por derroteros insospechados: los detectives se acaban

7 Este motivo temático de gran pujanza en la filmografía de Hitchcock se eleva a cotas de gran altura en Rebecca (1940), claro antecedente de Vértigo (1958). Por su parte, en la obra de Marías ya está presente en El ciclo de Oxford, plasmado en los pensamientos del personaje, que le hacen reflexionar sobre cómo el alejamiento físico del narrador (en la ciudad de Oxford) lleva consigo una distancia emocional, y con ella la imposibilidad de discernir si la mujer que quedó en España está viva o muerta en su memoria, o si los cuerpos ausentes se ven reemplazados por otras presencias corpóreas, en un incesante movimiento universal sustitutorio. 
enamorando de las mujeres a las que se les había ordenado perseguir, aunque finalmente los personajes femeninos mueren de manera fatal. Este esquema, cuya simplificación desvirtúa el amplio espectro de matices presentes en el filme y en la novela, ha de entenderse como punto de arranque para analizar la riqueza significativa que ofrecen estas obras. Como sostiene Marías al inicio de su novela:

La índole de los personajes no cambia nunca o eso parece, los de la realidad y los de la ficción su gemela, se repiten a lo largo de los siglos como si carecieran de imaginación las dos esferas o no tuvieran escapatoria (las dos obra de los vivos, a fin de cuentas, quizá haya más inventiva entre los muertos), a veces da la sensación de que disfrutáramos con un solo espectáculo y un solo relato, como los niños muy pequeños. Con sus infinitas variantes que los disfrazan de anticuados o novedosos, pero siempre en esencia los mismos (Marías, 2014: 11).

En Hitchcock el detective es Scottie, quien aquejado por la patología del vértigo o acrofobia, tras haber vivido una escena frenética y dramática de persecución por los tejados de San Francisco (en la que quedó prendido en la canaleta de uno de ellos), decide retirarse. Por su parte, Juan de Vere sigue el encargo del cineasta Muriel: si bien al principio le ofrece un trabajo de traducción, a la postre se desencadenará su actividad detectivesca. En cambio, en Vértigo el atractivo y perverso villano Gavin Elster urde todo el plan, con el fin de tener un coartada que le permita asesinar a su esposa. Las motivaciones, como puede apreciarse, son muy distintas en la novela y en el filme, si bien en la estructura subyacente se deja sentir un desenvolvimiento semejante de las acciones.

Vértigo (De entre los muertos) y Así empieza lo malo son historias de imitación, de simulación, de repetición. Si la idea de teatralidad o imitatio se vincula con Vértigo en la trama urdida por Elster (que representarán Scottie como detective y Judy como actriz que encarna el papel de Madeleine), en Así empieza lo malo el narrador Juan de Vere hace explícito el germen de la imitación y el gusto por la simple observación: "Tal vez yo imitaba ahora a criaturas de Hitchcock" (Marías, 2014: 191). Además, la historia está llena de Edurados Muriel y Beatrices Noguera, "empeñados uno tras otro en representar el mismo espectáculo y en reescribir el mismo relato melodramático" (Marías, 2014: 449). Al igual que Judy Barton en Vértigo (De entre los muertos), Beatriz Noguera también es una actriz: ambas dirigen la vida de aquellos a quienes aman. Sin embargo, Noguera no intenta cambiar a Muriel. Al contrario, es en ella en quien se opera el cambio (se asimila al gusto de su marido por el cine). Esta idea de teatralidad, de fingimiento, de tramas urdidas, aflora como una constante en las ficciones de Hitchcock y Marías, y viene a establecer una similitud entre las vidas reales y su imitación, entre la verdad imposible de asir y su representación ficticia. 


\section{MARCO HISTÓRICO, AMBIENTACIÓN Y ESPACIOS}

Más de cincuenta años separan las obras (literaria y cinematográfica) que aquí se proponen. No es extraño entonces que el surco del tiempo haya hecho estragos modificando no solo el germen de la ficción, sino también variando los condicionamientos históricos y culturales que motivan el acto creativo en Alfred Hitchcock y Javier Marías. Por lo tanto, fijaremos nuestro estudio en dos cortes diacrónicos diferenciados en la línea de la historia, vinculando sus contextos, estableciendo diferencias y, por extensión, colmando el horizonte significativo subyacente. En el nivel intradiegético (en el interior de la historia ficticia), los escenarios elegidos por Hitchcock y Marías son, respectivamente, el San Francisco de la década de los cincuenta, con su "sofisticada ubicación metropolitana" (Spoto, 2001: 340), y el Madrid de los años ochenta, de la movida, luego de que se pusiera fin a la dictadura franquista en 1975. En Marías, la representación de la movida madrileña como movimiento contracultural queda retratado en las salidas nocturnas de personajes como el doctor Jorge Van Vetchen.

Las épocas a las que nos trasladan ambas ficciones presentan un mundo en cambio, una ciudad que se está viendo modificada y que, por tanto, incita al personaje a cambiar su modo de concebir la realidad. En efecto, en Vértigo Gavin Elster, el marido que contratará a un espía para que siga a su mujer, sostiene que San Francisco ha cambiado y que aquello que le suscitaba una auténtica fascinación, ha ido desapareciendo. Se aprecia, por tanto, un sentimiento melancólico hacia el San Francisco bohemio impregnado de colorido y emoción. La ciudad es filmada "desde la perspectiva del turista" (Ponce, 2014: 335). De hecho, la primera parte del filme se concibe como un recorrido visual por distintos lugares: calles, colinas, Union Square, el Palacio de Bellas Artes, el bosque de secuoyas, el Golden Gate, los cementerios o las iglesias del pasado hispano. El espectador conocerá la ciudad al tiempo que James Stewart persigue a Kim Novak. Hitchcock precisaba de una localización concreta que ofreciera "un marco creíble y coherente de una historia que bebía del romanticismo del pasado" (Jiménez Pascual, 2011: 191), todo ello con un ritmo que alternara las escenas pausadas de conversación con el ritmo frenético de la persecución por las calles de un San Francisco impregnado de nostalgia, envuelto en un halo de fascinación ${ }^{8}$.

Por su parte, Así empieza lo malo rescata un fresco social del Madrid de la movida, en la década de los años ochenta, cuyo trasfondo concierne a la aprobación de la Ley 30/1981, de 7 de julio, con la que se reforma el Código Civil y se regula el matrimonio

8 Como sostiene Ponce (2014: 335), “Vértigo dotó a San Francisco de un aura audiovisual aún no superada, por lo que no es de extrañar que todo el cine posterior la tenga siempre presente a la hora de filmarla", tal como sucede en Instinto básico (Basic Instinct, Paul Verhoeven, 1992), Máxima ansiedad (High Anxiety, Mel Brooks, 1977) o Juego peligroso (Foul Play, Colin Higgins, 1978). 
que introducirá el divorcio en España. En este sentido, la novela muestra el contraste entre personajes de fuerte convicción religiosa (Gloria, la concuñada viuda de un hermano de Muriel) que resaltan el tradicionalismo de la España rural y católica, frente a "una sociedad urbana y en su mayor parte laica" (Martínez-Vasseur, 2004: 172) que se estaba fraguando en la década de los ochenta. Si bien Beatriz Noguera se acogerá al tradicionalismo ("Prefiero la palidez de este muerte andando al color del mundo entero. Prefiero demorarme en su palidez que vivir a la luz de los vivo", Marías, 2014: 158), se da un punto de inflexión en la trama con sus escarceos amorosos con el doctor Van Vechten, lo que desencadenará el desprecio de su marido y las sospechas de infidelidad.

Tanto en Hitchcock como en Marías, se abren las puertas del pasado: en la película este es el nombre del templete neoclásico que adorna el fondo del estanque en un parque de la ciudad (Trías, 1998: 132). En Marías el pasado se desvela con la historia del matrimonio entre Eduardo Muriel y Beatriz Noguera: él quiso romper su compromiso, pero ya era tarde por una carta ${ }^{9}$ que Beatriz fingió no haber recibido nunca ${ }^{10}$. Puede entonces considerarse a Muriel como una contrafigura de Orfeo, quien a diferencia de Scottie que indaga en el pasado, prefiere desvincularse de esa vida remota: "Me olvidaré de lo que se perdió en el camino, es tarde para retroceder y esa senda ya no es la mía. Avanzaré por esta sin mirar atrás y procuraré no lamentarme" (Marías, 2014: 501). Si bien Muriel no quiere abrir las puertas del pasado y prefiere no mirar atrás, al final afloran el arrepentimiento y la culpa, pues siente que ha desperdiciado su existencia lejos de quien amaba, sacrificada tan solo por el sentido de la responsabilidad y el compromiso con Beatriz. Si en Marías el pasado se vincula al silencio impuesto tras el final de la dictadura franquista, en Hitchcock, esas puertas del pasado son "las que intentará abrir, al final del

9 Las ficciones de Hitchcock y Marías tienen en común la historia sobre cómo un mensaje (una carta) puede modificar el destino humano: Los personajes femeninos (Judy Barton y Beatriz Noguera) prefieren no revelar el contenido de la carta: Mientras que Judy es la ejecutora de tal acción, pues trata de escribirle a Scottie para revelarle que todo este tiempo se ha hecho pasar por la difunta Madeleine y, finalmente, rompe la carta, en el caso de Beatriz Noguera, ella fue la receptora de una carta que fingió no haber recibido nunca. En ambos casos, por tanto, la ocultación del mensaje de la epístola (o su fingimiento) viene a modificar el destino humano: mantiene en el engaño a Scottie y Muriel. Como sostiene este último personaje, "son demasiadas las vidas configuradas sobre el engaño o el error" (Marías, 2014: 504).

10 En la novela se explica cómo Beatriz Noguera tuvo que alejarse de Muriel meses antes de su boda para cuidar de su padre -quien finalmente muere-. En ese tiempo Muriel, que estaba rodando su segunda película, conoció al amor de su vida, pero tuvo que renunciar a él. Muriel envió una carta a Noguera rompiendo su compromiso, carta que al parecer nunca llegó a manos de Beatriz. Sin embargo, en las páginas finales de la novela Beatriz revela su secreto: calló, nunca dijo nada, nunca confesó haber recibido la carta. Muriel hubiera preferido permanecer en el engaño, pero ese silencio modificó toda su existencia: "Cerré la puerta sabiendo que dejaba pasar de largo el apasionamiento, el amor de mi vida" (Marías, 2014: 495). Al igual que Scottie, Muriel sacrifica el amor de su vida, añorando la vida que fue desechada como si se tratara de "una ensoñación o una fantasmagoría" (Marías, 2014: 501). 
film, Scottie al conducir a la resucitada Madeleine, por segunda vez a la misión de San Juan Bautista, hasta arriba de la torre campanario" (Trías, 1998: 132).

\section{A LA BÚSQUEDA DE UN DETECTIVE: GAVIN ELSTER Y EDUARDO MURIEL}

Toda la ficción erigida por Hitchcock y Marías sería inexistente si Gavin Elster y Eduardo Muriel no hubieran contratado a un espía para seguir a sus mujeres ${ }^{11}$. Este hecho central aunque anodino se sitúa como verdadera fuerza motriz, desencadenante de los hechos acaecidos. A este respecto, el filme y la novela presentan dos escenas homólogas que tienen lugar en los despachos de Elster y Muriel, donde han concertado una cita con los que ellos consideran que serán los detectives o espías ideales para vigilar a sus mujeres. Ya en la novela de Boileau y Narcejac sobre la que se construye Vértigo, es patente la entrevista entre ambos personajes, en el antiguo piso del detective, quien es visitado por un antiguo condiscípulo (Sanabria, 2013: 85).

La escena del diálogo o "conversación (banal para la intriga)" (Company y Sánchez Biosca, 1985: 50) entre Scottie y Elster, su antiguo amigo de universidad, que se desarrolla en el despacho de éste, evoca de manera subrepticia la conversación entre el cineasta y Juan de Vere en el despacho de Eduardo Muriel. La novela de Marías arranca casi en los capítulos iniciales con un encuentro entre estos dos personajes. Sin embargo, la diferencia capital con respecto a Hitchcock es que en la novela el encargo se posterga, pues Muriel al principio requiere a De Vere para unos encargos de traducción. Solo cuando se han leído doscientas páginas de la novela — cuando De Vere ya ha espiado a Noguera en el santuario de Darmstadt o en la plaza del Marqués de Salamanca-, Muriel desvela la encomienda: que se haga compañero de farras de Van Vechten. En virtud de esa dilación en el encargo, es frecuente la "divagación conjetural" (Grohmann, 2011: 106) de Muriel, quien se expresa "como si se le hubiera cruzado un pensamiento" (Marías, 2014: 22), hecho que le resta cierta agilidad al diálogo entre personajes

Si en Vértigo Elster expone los motivos directamente y muestra de modo explícito su requerimiento de encargo, se distancia esta visión del discurso digresivo de Muriel, presentado como excursus del personaje, con la pipa en una mano y en la otra la brújula, pues tal como reflexiona de Vere: "Está dudando si contarme o no de qué se trata, de qué se ha enterado a su pesar. Teme que si me lo confía todo parecerá más real o más cierto" (Marías, 2014: 32). Muriel apenas revela información a De Vere: únicamente le cuenta que un amigo de hace años ya no es como era, por lo que teme una traición relacionada con

11 Hay que puntualizar que en Así empieza lo malo, Muriel no pide a Juan de Vere que espía a su esposa, sino que vigile al Doctor Van Vechten, por acuciantes sospechas de calumnia en el pasado. Sin embargo, De Vere rebasa las directrices del encargo y espía por su cuenta a Noguera. 
falsas noticias o calumnias. Aunque De Vere somete a un interrogatorio a Muriel, la única información a la que accede es el nombre del amigo: el Doctor Van Vechten. Será, por tanto, la curiosidad del joven traductor la que le lleve a introducirse en el espionaje.

Como se aprecia, tanto en la obra literaria como en la producción cinematográfica, hay un encargo relacionado con el espionaje y el objeto que se ha de espiar es el mismo: una mujer. Ambos (Elster-Muriel) ofrecen a los detectives (Scottie-De Vere) los antecedentes sobre sus mujeres. En el caso de Vértigo, sostiene Gavin Elster que aunque son una pareja feliz, teme que alguien muerto (un ser del pasado) le haga daño. Elster plantea el interrogante fundamental: "¿Puede un ser del pasado tomar posesión de un ser del presente?: "A lo mejor me está hablando de algo [...] y de pronto las palabras dejan paso al silencio, una nube le cubre los ojos y queda sin expresión, está en otra parte, lejos de mí, es una desconocida, la llamo, y no me oye siquiera; luego, con un prolongado suspiro, vuelve..." (Hitchcock, 1958).

El pretexto que elige Elster para que Scottie acceda a vigilar a su esposa es que ya no es ella, sino que "ha tomado posesión de su espíritu" (Trías, 1998: 130), un muerto que, como se comprobará en las escenas sucesivas del filme, es su bisabuela Carlota Valdés. Sin embargo, en la segunda parte del filme que arranca tras la caída de Madeleine desde la torre campanario, se atestigua que el encargo había sido un pretexto más de la trama teatral urdida por Elster para asesinar a su esposa: el marido eligió a Judy (su amante) por el parecido con su esposa para que interpretara el papel de Madeleine, y a Scottie por su acrofobia para que interpretara el papel de espía. De las palabras que Elster profiere a Scottie lo único real es la historia de Carlota, la bisabuela de Madeleine, por lo que tal motivo le sirve para urdir la trama, asesinar a su esposa y fingir que se ha suicidado:"Elster le pide a Scottie que siga a su mujer, Madeleine, en sus extravagantes paseos en coche, debidos al parecer a una incipiente esquizofrenia. Esta se presenta con el curioso síntoma de la posesión de su mente y de su ánimo por parte de una antepasada, Carlota Valdés, de la que no tiene noticia alguna" (Trías, 1998: 18).

Por lo tanto, las motivaciones que conducen a estos personajes a buscar a un detective que actúe como espía de sus mujeres (o de alguien cercano a la mujer: el Doctor Van Vechten), es muy distinta. Si el acicate en Hitchcock es todo un teatro ideado cruelmente por Gavin Elster, en el caso de Marías se vincula con la sospecha de calumnias volcadas sobre el Doctor, si bien la curiosidad de Juan De Vere lo llevará a descubrir la infidelidad que Beatriz Noguera destina sobre su esposo. En Vértigo, por su parte, prevalece la obsesión por acceder a la totalidad del conocimiento, pues es la historia de "un hombre que desea no solo resolver un misterio y salvar a una mujer, sino también ejercer el control que proviene del conocimiento" (Spoto, 2001: 350):

Los modos de espiar de Scottie y De Vere establecen divergencias que otorgan singularidad a cada una de las obras. Si en Hitchcock las escenas de espionaje se dan 
en su totalidad en espacios abiertos, en el puro fluir de la ciudad de San Francisco, en Marías es frecuente el espionaje en espacios cerrados: la casa, en la escena memorable en que el joven traductor abre la puerta y encuentra a Beatriz de espaldas en la cocina. Mientras que Scottie realiza la persecución en coche — hasta que llegan a los lugares donde Madeleine/Judy se desliza por los laberintos de su locura (interpretada)—, en la novela de Marías Juan de Vere espía mientras camina por las calles de Madrid.

A este respecto, la diferencia fundamental viene dada por las actividades de contemplación furtiva que realiza De Vere dentro de la casa de Muriel y Noguera. Aunque el cineasta le ha indicado que siga a su mujer cuando salga de casa, la curiosidad de Juan de Vere rebasa todos los límites del encargo para elevarse hasta su propia complacencia, por el mero placer de observar y asistir a la "contemplación de lo íntimo" (Sanabria, 2011) de Beatriz Noguera.

Memorables son, a este respecto, los capítulos en los que De Vere describe cómo su ojo furtivo, su mirada indiscreta atisbaba a la prominente Beatriz, no con voluntad fetichista como en Hitchcock, sino para contemplar su carne trémula e inmiscuirse en su vida, por una suerte de "incontinencia visual sobrevenida" (Marías, 2014: 260). Si ya la segunda noche que pernoctó en el piso de la calle Velázquez -—con el larguísima pasillo en forma de $\mathrm{U}$ - descubrió un hueco contiguo a su habitación (separado por una puerta), vio en él un mecanismo de salida sin entrada, para asomarse y ver a Beatriz caminar por el pasillo. Como espectador, como testigo indiscreto que observa, De Vere cae en el vértigo de la contemplación, en la imposibilidad de abandonarlo: "Como espectador prefería que apareciera y asistir a más representación, una vez que uno empieza a mirar y escuchar ansía que todo siga. Es una adicción instantánea si la curiosidad se despierta, un veneno más irresistible que el de obrar y participar" (Marías, 2014: 88).

En el filme de Hitchcock, la primera persecución de Scottie tras el coche de Madeleine ofrece el recorrido laberíntico que el espectador persigue con inquietud y zozobra. Prevalece, en palabras de Stoichita (2006: 262), el "pattern narrativo de la persecución". Así pues, el espectador se convierte en un espía en tercer grado, que traza el recorrido seguido por Scottie y, a su vez, por Judy.

En Marías, en cambio, es el narrador De Vere quien —alejado en el tiempo y en el espacio - rememora su actividad en la casa del matrimonio infeliz que formaron un día Eduardo Muriel y Beatriz Noguera. En el relato de las escenas de persecución del joven traductor, está presente el filme Con la muerte en los talones, que él mismo menciona de manera explícita. Además, De Vere no realiza en soledad todas sus actividades: cuando Muriel, el Doctor Van Vechten y él sospechan que Beatriz está en peligro (en un hotel donde podría acabar con su vida), corren apresurados a evitar el desastre.

Pudiéramos entonces preguntarnos cómo es el desenlace de estos personajes. En Hitchcock, tras la muerte de Madeleine, el perverso Gavin Elster abandona San Francisco, 
por lo que la historia se cierra para siempre. Como sostiene Truffaut (1974: 11), Hitchcock organiza sus intrigas a partir de coincidencias que otorgan fuerza y alimentan el drama, para luego desanudarlo velozmente hasta el extremo paroxismo. En Marías, en cambio, asistimos a una complejidad mayor para poner punto y final a la actividad detectivesca. Esta riqueza en matices se produce por los lazos que De Vere ha establecido con esa familia: no solo con el cineasta Muriel, sino con su esposa Beatriz Noguera (lazos carnales, sentimentales, fantasmales) e incluso con su hija mayor (quien es presentada como una pintura, un retrato inmóvil, sin corporeidad, pero que irá adquiriendo formas y volúmenes más definidos al final de la obra, sobre todo cuando se una sentimentalmente a Juan). En De Vere se ha inyectado el aguijón de la curiosidad, por lo que quiere concluir con éxito el espionaje que se le ha encomendado.

En síntesis, Scottie y De Vere - personajes narradores situados en el nivel intradiegético (Stam, 1999: 120)—, se perfilan como criaturas de ficción confinadas al espionaje, si bien son títeres absurdos de tramas previamente urdidas. El conocimiento de la verdad que subyace en las vidas de otros personajes dotará de un tono trágico el final del filme, y de una perpetuidad a la novela de Marías, con la unión sentimental de Juan de Vere con Susana, la hija (o el fantasma) de Beatriz Noguera.

\section{JUDY-MADELEINE, BEATRIZ-SUSANA: VIDAS SUCESIVAS, DESDOBLAMIENTO Y FANTASMAS}

Desdoblamiento, suplantación o vidas imitadas - conceptos que se han ido espigando a lo largo de este estudio- se colman de significación en los personajes femeninos de las ficciones de Hitchcock y Marías. Dos son las mujeres que en cada una de estas historias circundan la vida de los detectives (Scottie y De Vere), doble es el abismo al que se asoman, en la tensión vida-muerte que resulta inherente a la perpetuidad. El sentido de la repetición ${ }^{12}$ otorga a las ficciones una textura de simulacro, de bucle infinito, de espejo deformado y deformante:

La estructura precisamente dual -tan estilizada en el arte, aquí retratada a través de desdoblamientos, de parejas espantosas (Lisa y Thorwald) como dice Javier Marías en "Todas las almas", de simulacros y deformaciones, de reflejos especulares, de proyecciones múltiples y variadas- define la dinámica visual, que condensa una exploración de las posibilidades psicopatológicas de la conciencia (Sanabria, 2013: 199-200).

12 La estructura de Así empieza lo malo ofrece una simetría magistral en el tratamiento de distintos motivos: dos son las muertes en acciente de coche cerca de Ávila (la concuñada, viuda de un hermano mayor de Muriel, y Beatriz Noguera. 
Esta idea que se enuncia a propósito de La ventana indiscreta, se hace extensible a Vértigo y a la narrativa de Javier Marías. De un modo similar a como sucede en Todas las almas, en Así empieza lo malo prevalece "el extraño gusto por la repetición, volver al mismo cuerpo y regresar y volver" (Marías, 2014: 98), con una objetualización fetichista del cuerpo amado. La mujer es focalizada desde la mirada de los detectives con un auténtico fetichismo ${ }^{13}$, con verdadera veneración y culto, que sobrepasa los límites de la mirada hacia lo que Deleuze (1987: 39), a propósito del cine de Hitchcock, denominó una "conciencia-cámara".

Si bien prevalece la ritualización extrema del físico (maquillaje, peinado, vestuario) de Madeleine-Judy en Vértigo (De entre los muertos), esta concepción se desdibuja en Así empieza lo malo, donde Beatriz Noguera es presentada como una suerte de ser fantasmal, condenado a una existencia gris junto a su marido, el cineasta Eduardo Muriel. Destaca, por tanto, el perfil físico de la mujer hitchcockiana, que roza el delirio. La belleza ritual de los personajes femeninos filmados por Hitchcock se vincula con los ritos funerarios: "Scottie se halla prendido y prendado de un fantasma femenino que tan pronto se revela en toda su magnificencia como se evapora en la total irrealidad inane; a la nihilidad conduce, sin embargo, su propia revelación fascinante" (Trías, 1998: 146).

Pese a que una de las líneas interpretativas que mayor pujanza han adquirido en el análisis de Vértigo remite al sustrato mítico y romántico ${ }^{14}$ (Orfeo y Eurídice, Tristán e Iseo ${ }^{15}$, Pigmalión y Ofelia) de la historia entre Scottie y Madeleine-Judy, Hitchcock ofrece los complejos míticos tamizados o disfrazados. Se sugiere sin hablar, se muestra sin decir, se intuye sin racionalizar. Como Orfeo ${ }^{16}$, Scottie desciende al infierno (de su propia locura) para salvar a Madeleine, la mujer que ama: "El detective, con el cuerpo de Madeleine en sus brazos, parece emerger de la profundidad del Averno, de un infierno acuoso, neptuniano, de donde extrae el cuerpo inane de una mujer mítica que alza hacia arriba" (Trías, 1998: 150).

13 "La rubia belleza de Madeleine es, en Vértigo, una máscara que refrenda su naturaleza fetichista. Por debajo del rostro nada hay; tan sólo un dispositivo escénico que tiene a Judy por sustento; esta es la percha que aguanta la hermosa máscara. Bajo el rostro de la máscara subyace el vacío de un ente ingrávido sostenido en volandas por el cuerpo y el alma real de Judy, la muchacha solitaria perdida en una habitación de hotel de segunda categoría en la ciudad de San Francisco" (Trías, 1998: 104).

14 Según Spoto (2001: 350) Vértigo responde a los conceptos románticos de inalcanzabilidad, inmolación y condenación.

15 Jiménez Pascual (2011: 199) señala la importancia de la leyenda medieval de Tristán e Iseo en el sustrato mítico del filme de Hitchcock: la pasión amorosa, el triángulo de personajes (Scottie-Madeleine, Judy-Elster y Tristán-Iseo-Rey Marco de Cornualles).

16 James Stewart se ve impelido por "el deseo de arrebatar a Eurídice de las potencias infernales, propiciando su resurrección" (Trías, 1998: 22). 
El rescate de Scottie, subiendo por el malecón del embarcadero y sujetando el cuerpo yacente de Judy, deja sentir una blancura prístina, marmórea, con el tono mortecino de su piel que contrasta con la oscuridad (azul violeta) de su vestido. En Marías no se da este sentido de la salvación del muerto, de abrir las puertas del pasado ${ }^{17}$. Si bien Juan de Vere salva del suicidio a Beatriz Noguera, al escenario del crimen también acude su marido, Eduardo Muriel, por lo que resulta imposible concebir este sentido órfico de descensus ad inferos que subyace en la configuración temático-simbólica del filme de Hitchcock. Sin embargo, es visible la idea de que al salvarle la vida a una mujer, puede apropiarse de ella, siente que le pertenece: "Soy una extensión de Muriel, lo ha dicho ella" (Marías, 2014: 384).

En una línea de fuerza semejante, el suicidio de los personajes femeninos se alza como motivo común en las ficciones de Hitchcock y Marías, con la consecuente salvación de los detectives. En el intento de suicidio de Madeleine (cuyo papel como actriz lo representa Judy), el personaje está imitando a su bisabuela Carlota Valdés, otorgándole al acto una "significación sagrada, religiosa" (Trías, 1998: 149), arrojando flores blancas sobre la superficie del agua, en una reminiscencia posible de la muerte de Ofelia dotada de una innegable simbología cromática ${ }^{18}$. También en Así empieza lo malo Beatriz Noguera intenta suicidarse en una bañera. De nuevo aflora el motivo del agua y la purificación, si bien en Así empieza lo malo no adquiere un tenor sacrificial, sino que el suicidio se presenta como una forma de escapar del infierno al que le conduce a Beatriz su existencia mediocre junto a Eduardo Muriel.

Si en Hitchcock se vislumbra el sustrato mítico de Pigmalión-Galatea cuando Scottie se alza como transformador de Judy Barton en Madeleine Elster, transmutando a una muchacha sencilla y plebeya en un ser refinado y elegante, "dando vida nuevamente a un ser muerto" (Trías, 1998: 169), en Marías prevalecen las repeticiones sucesivas por

17 En uno de los capítulos finales de la novela de Marías, Noguera abre la puerta (de manera literal y no simbólica) cuando termina la conversación entre De Vere y Muriel. Pero estas puertas no son las del pasado, no remiten a Orfeo. No hay Eurídice a la que rescatar. Tras la conversación, se marchan a Soria y olvidan su existencia marchita en Madrid.

18 La motivación cromática del plano de Vértigo en que la actriz Judy "finge" suicidarse (interpretando a Madeleine) ha sido revestida de significación temporal y simbólica por Eugenio Trías, con la aureola que desprende el color verde en torno al personaje: "Luces de color verde esmeralda que se avienen a la perfección con el colorido chillón que se puede asociar con la muchacha. Verde es el traje que lleva Judy la primera vez que se encuentra con Scottie. Esas luces de neón, en un momento mágico de la cinta, sirven para aurolear de electricidad ionizada el cabello y la frente de Scottie; y sobre todo su mirada, poseída por el deseo. Eso ocurre justo en el instante crucial en que se produce la escena suprema del rito de la transfiguración: cuando Judy se metamorfosea radicalmente en Madeleine, consumando su resurrección "de entre los muertos", adelantada por un halo surreal de color verde. Verde es, en efecto, el color apropiado para toda metamorfosis. Color de la memoria (del pasado) y de la esperanza (de su rescate y resurrección" (Trías, 1998: 22). 
la semejanza física. Si en Hitchcock el sorprendente parecido físico vincula las vidas de Madeleine y Judy ${ }^{19}$, en Marías será el parentesco madre-hija (Beatriz Noguera y Susana) el que permita a la mente asociativa de Juan de Vere trazar una homología entre los personajes. De este modo, el fantasma de la difunta Beatriz Noguera parece perpetrarse en su hija, por su parecido físico y porque Juan de Vere ha yacido con las dos, de modo que no sabe si se está acostando con una o con la otra, o si el hijo que esperaba Beatriz Noguera sería el suyo propio (Marías, 2014: 530-531).

En Vértigo el momento de revelación de esa semejanza entre las dos mujeres se produce cuando Scottie descubre a Judy saliendo del trabajo y comprueba al instante "el parecido que la une a Madeleine" (Trías, 1998:22), la mujer difunta que se arrojó de la torre campanario, en un acontecimiento fatal en la iglesia de la Misión de San Juan Bautista. En esa evocación o rememoración que la mujer viva le suscita sobre la muerta, existe una suerte de ofelización (Morales Peco, 2011: 80) del personaje femenino: una delectación sobre la mujer muerta ${ }^{20}$. Se alza, por tanto, como una recreación del motivo pictórico de la "Ofelia" (1852) de Millais, en la que el cuerpo de la joven muerta se vislumbra sobre la superficie flotante de las aguas, adornado pétalos, en una imagen de melancolía y delirio deudor de la tragedia homónima shakespereana. También en la novela Juan De Vere llega a sentir auténtica veneración por Beatriz (la adora como algo inalcanzable por su madurez) y aflora un sentimiento velado de conmiseración, aunque en ningún caso se llega al extremo del culto a la difunta (recuérdese Ligeia de Poe), colmándose de una belleza exacerbada que deriva en la categoría estética de lo sublime: la belleza se desborda hacia la "sublimidad trágica del amor-pasión" (Trías, 1998: 73), con un sentido de "el Ideal, lo Inalcanzable, lo Infinito" (Castro de Paz, 1992: 47) en Vértigo.

Quien idea una creación irreal asume el riesgo de estar dando vida a un ser de corporeidad dudosa, un "fantasma encarnado o ectoplasma", un "esqueleto resucitado", "una presencia enigmática" (Trías, 1998: 146), tal como se muestra Judy Barton ante los ojos del espectador y ante la mirada de Scottie en un doble registro (Company, 1987: 41), con una existencia "irisada y nimbada de irrealidad" (Trías, 1998: 146). Es, por tanto, un espejo o espectro venido de entre los muertos. En palabras de Castro de Paz (1999: 37), la representación de la amada no depende tanto de ella misma cuanto del fantasma que Scottie construye sobre ella. El juego entre la realidad y la ficción, el rostro real y su máscara

19 Se aprecia a su vez un palpable parecido físico de Madeleine con su bisabuela Carlota Valdés (tal como revela el retrato que Madeleine observa en el museo), en un triple juego de espejos y vidas sucesivas: Carlota Valdés-Madeleine-Judy. Ese "juego de la mirada” vincula Vértigo con La ventana indiscreta y EI proceso Paradine (González Requena, 1989: 161)

20 Resulta memorable la escena del beso entre Scottie con la mujer rubia, que se asemeja a una mujer muerta, de la que se percibe la palidez, el tono lívido de su rostro casi mortuorio: el cabello rubio, casi albino, y el moño en espiral. 
apela a la tensión entre Madeleine-Judy, con el consecuente engaño y falsificación que implica dotar de vida a un ser irreal. La existencia fantasmal se da en Hitchcock en una triple puesta en abismo: Carlota Valdés, bisabuela de Judy, es el fantasma sobre el cual se sustenta la trama urdida por Elster.

La tragedia final de Vértigo (De entre los muertos) radica, pues, en la "absoluta falta de un objeto" (Company y Sánchez Biosca, 1985: 54), hecho que distancia al filme de Hitchcock de la novela de Marías, donde De Vere proyecta su deseo sobre un ser real, en Susana, la hija de Beatriz, "una pintura, una representación inanimada" (Marías, 2014: 133). Los hijos (Susana, Alicia y Tomás) son copias, sucesiones de Beatriz, si bien aparecen como sujetos existentes. Pero el deseo de Scottie se sustenta sobre la ausencia, sobre un ser irreal, ficticio en una "mirada imaginada al campo ausente" (Bonitzer, 1982: 106). Si en Vértigo, "la mirada lanzada hacia el objeto de deseo, además de imposible, estaba hecha con ojos prestados" (Company y Sánchez Biosca, 1985: 54), significa que Scottie persigue algo que no existe. Ello trunca el destino del personaje y lo sume en la desolación, en una pérdida irremisible que impide recuperar la imagen de la amada ni siquiera mediante la falsificación o composición de otro ser (Judy), con claras resonancias del Pigmalión mítico o de Hoffmann ${ }^{21}$.

Por su parte, el tema del fantasma en Marías se vincula con los lazos carnales que De Vere ha mantenido con dos personajes de la misma estirpe: madre e hija, en una "íntima lealtad fantasmal" (Marías, 2014: 525). La predilección de Marías hacia este motivo recurrente en su obra se expresa en el prólogo a Vida del Fantasma (1995), como una "representación del pasado" (Roman, 2007: 155). Ese fantasma real que es Beatriz, repetido y postergado de manera sucesiva en su hija Susana, resulta imposible en Hitchcock. Aunque Scottie se enamora de una "criatura de ficción, trazada y diseñada por Gavin Elster e interpretada por Judy Barton" (Trías, 1998: 147), ello no impide "la cristalización de su deseo erótico" (Trías, 1998: 147).

Tanto en el filme de Hitchcock como en la novela de Marías, se produce una exaltación del deseo humano y su carácter insaciable, que se plasma en la sustitución de los objetos de referencia a través del delirio y la búsqueda (González Requena y Ortiz de Zárate, 1995: 16-17). La ficción hitchcockiana construye una sólida simbología: el moño en espiral como mise en abyme (mise en scene) con la mujer del cuadro, una contemplación de la mujer real sobre sí misma, que se contempla en la obra de arte; la espiral como retorno al pasado, representación en miniatura (microescena) del vértigo (la circularidad). De un modo similar, los retratos adquieren gran relevancia en Así empieza lo malo: fijan la

21 Sanabria (2013: 104) vincula a Madeleine de Hitchcock con Olimpia de "El hombre de arena" (1817) de E.T. A. Hoffmann, donde Olimpia es la autómata fraguada por Coppelius de modo semejante a como Judy es la mujer "resucitada" por Scottie. 
edad de un personaje y lo inmortalizan en un momento concreto en el tiempo, según un sentido fantasmal que inmoviliza su figura.

Al final las consecuencias son más trágicas en Hitchcock: en Marías Beatriz Noguera muere (en un terrible accidente de tráfico), por lo que su hija viene a ocupar su lugar en la vida de Juan de Vere. En Hitchcock, en cambio, la escena del campanario en la torre de la Misión de San Juan Bautista revela el estrangulamiento (Elster arrojó el cuerpo de su esposa). Scottie como detective intenta evitar el desastre, pero no llega a tiempo a causa del vértigo. Esa inevitabilidad del desastre y la culpa que arrastra Scottie ensalzan la tragedia en el filme, frente a la suplantación en la figura de la hija, como se narra en la novela de Marías.

\section{DEL (MELO)DRAMA POLICÍACO AL HUMOR: RAZONES PARA UN FINAL}

Se aprecian, pues, dos motivaciones muy distintas en el tratamiento de la mujer, hecho que condiciona el desenlace de las obras. La vertiente humorística de Así empieza lo malo resulta inexistente en Vértigo. Ni un esbozo de sonrisa puede captar en el espectador el melodrama que Hitchcock presenta tras la urdimbre teatral de Gavin Elster. Resultaría macabro que Scottie apelara al humor tras haber visto cómo Madeleine (la verdadera esposa de Elster) ha sido arrojada al vacío desde lo alto de la torre campanario, sin que el detective haya podido impedirlo a causa del vértigo. La actitud de Scottie revela la majestuosidad fúnebre de quien ha perdido aquello que más amaba, en un ritornello angustioso, una melodía de culpa por las terribles consecuencias a que ha conducido su acrofobia. Por esta razón, Scottie se redime del yugo de la culpa a través del ritual sagrado de la veneración a la mujer muerta. Esta revelación o "anagnórisis trágica" (Trías, 1998: 86) cambia el rumbo de la historia e impele a Scottie a ritualizar el cuerpo de la difunta a través de una delectación morosa hacia la que considera su encarnación, su sucesión en vida: la bella Judy Barton que había interpretado el papel de Madeleine durante la primera parte del filme.

El único personaje que ofrece tintes humorísticos en Vértigo es Midge, la pintora y antigua novia de Scottie. Este personaje es retratado con poca profundidad, como un mero gozne en el engranaje de la trama que permite a Scottie contrastar el verdadero melodrama de la historia de Judy/Madeleine con el cariz risible de las escenas en el apartamento de Midge, que actúan como anticlímax. En efecto, Midge "sintetiza en clave humorística la historia de la resucitada Carlota Valdés" (Trías, 1998: 147), si bien Scottie no muestra complacencia ante tal suerte de broma macabra. El humor — si acaso pudiera relucir en Vértigo - lo hace a modo de contrafaz, tras la gravedad y el tenor trágico de las escenas mortuorias o de tensión tras la persecución llevada a cabo por Scottie. 
Cuando el Kronos deviene Kairos (Kermode, 1983: 52), el momento de revelación se fija en la imagen de la monja como deus ex machina. El motivo de la monja ridícula y grotesca, aparece en la escena de espionaje del santuario de Darmstadt en Marías, cuando le pregunta qué hace encaramado al árbol; en Hitchcock sella la tragedia con el tañido de las campanas, aderezando el signo trágico con cierto humor, tras la escena en que Judy cae al vacío desde lo alto de la torre campanario. Por ello, aunque Vértigo se acoge a los patrones de la novela criminal, se distancia de ella al introducir una modificación radical en su configuración fílmica: "el momentáneo cambio de focalización y el adelanto del final de los acontecimientos al espectador" (Sanabria, 2013: 127), con el cambio de fortuna que conduce a la "ironía trágica" (Trías, 1998: 162). Judy muere trágicamente al arrojarse desde lo alto de la torre. Cae al vacío, desciende al infierno, encuentra la muerte, con el mismo final de Madeleine (a quien antes había representado):

La ironía consistirá en ese giro en virtud del cual el terapeuta aparece, al final, como el verdadero enfermo. El carácter trágico de este giro se revelará en el hecho de que la persona a la cual el detective pretendía curar de la locura es justamente la misma que, en virtud de la enfermedad del detective, acaba arrojándose al vacío. Es más, el detective pasa de ser el salvador de Madeleine a ser algo semejante a la causa involuntaria de su presunta muerte (Trías, 1998: 163).

La cura del vértigo en Scottie se produce en virtud de su obsesión que emerge como una "enfermedad espiritual" (Wood, 1968: 106). Scottie encarna la ambivalencia trágica del vértigo: "querer y no querer a la vez arrojarse a un vacío que teme y le fascina" (Trías, 1998: 164), en una suerte de "identificación-alineación con/en el objeto amado" (Company y Sánchez Biosca, 1985: 48). En la escena final, Scottie emerge como "eterno espectador de una caída definitiva" (Trías, 1998: 164).

La tragedia adviene cuando el mysterium fascinans que impregna de belleza el filme deviene mysterium tremendum (Trías, 1998: 165), cuando el abismo sube y se desborda (Trías, 1982: 14). La cara oculta de la belleza esconde un rostro siniestro y melodramático cuando la tragedia se alza hasta cimas inusitadas. Se ha perfilado el drama hasta coronarse como irreversible.

Hay en Hitchcock y en Marías una tendencia hacia la muerte y el aniquilamiento de las figuras femeninas. Su trágico destino queda sellado por un final luctuoso, bañado de muerte. Si en Marías la muerte se ve como un acontecimiento que forma parte de la vida, como un hecho irreversible que causa dolor pero que se comprende como algo inevitable e inherente a la condición humana, en la película de Hitchcock Scottie no acepta el final y termina "abrazando el vacío" (Trías, 1998 194), con la mirada puesta en el 
abismo desde el campanario en el que segundos antes ha visto a Judy despeñarse y, con ello, sellar su trágico destino.

\section{CODA: HACIA UNA HOMOLOGÍA ENTRE LENGUAJES}

Desde el modo de concebir los estudios comparatistas en el siglo XXI, reescribir no se limita tan solo a adaptar de manera fidedigna una obra literaria. En esta línea, este estudio ha abordado cómo en Así empieza lo malo (2014) de Javier Marías se aprecian modulaciones, atisbos, giros argumentales, personajes afines y una mirada compartida hacia el universo de ficción que ofrece una indudable homología con el filme Vértigo (1958) de Alfred Hitchcock.

Una vez delimitados los contextos y marcos histórico-espaciales sobre los que se sustenta la ficción en ambas producciones artísticas, se han abordado los lazos temáticos (el espionaje, el amor y su pulsión de muerte, el hilo de continuidad entre los vivos y los muertos, o el secreto profundo bajo el que subyace la verdad) que comparten la novela de Marías y el filme de Hitchcock. En esa cosmovisión común se han desgranados los principales ejes que vertebran ambas ficciones literarias y filmicas.

La capacidad analógica del cine para ofrecer modulaciones propias del género novela en su universo visual, se esclarece a la luz de las ideas de Jakobson, quien abogó por la condición metonímica del cine y su capacidad para asimilarse a otros lenguajes: "El arte cinematográfico [...], en esencia, es profundamente metonímico, es decir que utiliza de manera intensa y variada el juego de las contigüidades" (1981: 132). Metonimia o analogía no son sino modos de concebir desde el ámbito de la reescritura los procedimientos transductivos que singularizan las investigaciones sobre novela y cine. Esta suerte de narratología comparada actúa a partir de contigüidades, simetrías y semejanzas mediante las cuales la imagen ha de significar casi lo mismo que la palabra. La búsqueda de la ósmosis o los procedimientos analógicos como fin último de la Literatura Comparada abre cauces a la reflexión en el quehacer filológico, otorga sentido al avance de las relaciones entre lenguajes artísticos y, en síntesis, ofrece una nueva mirada siempre joven y atenta - hacia la impronta que los imaginarios filmicos forjaron sobre los mundos narrativos. 


\section{REFERENCIAS BIBLIOGRÁFICAS}

BALLÓ, J. y PÉREZ, X. (1997). La semilla inmortal. Los argumentos universales en el cine. Barcelona: Anagrama.

BONITZER, P (1982). Le champ aveugle. Essais sur le cinéma. París: Cahiers du CinémaGallimard.

CASTRO DE PAZ, J. L. (1992). “Cinemateca de Vértigo. El delirio de la mirada: Vértigo (1958, Alfred Hitchcock). Análisis de una secuencia". Revista de Cine 6, 43-48. (1999). Alfred Hitchcock. Vértigo/De entre los muertos. Barcelona: Paidós.

COMPANY, J. M. y SÁNCHEZ BIOSCA, V. (1985). “La imposible mirada”. Contracampo 38, 46-54. COMPANY, J. M. (1987). El trazo de la letra en la imagen. Texto literario y texto filmico. Madrid: Cátedra.

DELEUZE, G. (1987) [1985]. La imagen-tiempo. Estudios sobre cine 2. Barcelona: Paidós. DOLEZEL, L. (1999) [1998]: Heterocósmica. Ficción y mundos posibles. Madrid: Arco / Libros. GONZÁLEZ REQUENA, J. (1989). "Viendo mirar (La mirada y el punto de vista en el cine de Hitchcock)". En Alfred Hitchcock, J. Luengos (ed.), 148-163. Oviedo: Fundación Municipal de Cultura.

GONZÁLEZ REQUENA, J. y ORTíZ DE ZÁRATE, A. (1995). El espot publicitario. Las metamorfosis del deseo. Madrid: Cátedra.

GROHMANN, A. (2011). Literatura y errabundia (Javier Marías, Antonio Muñoz Molina y Rosa Montero). Amsterdam-New York: Rodopi.

GUBERN, R. (2013). “Prólogo". En Las adaptaciones subliminares. Tres obras maestras de Alfred Hitchcock, C. Sanabria (ed.), 9-10. Madrid: JC.

GUILLÉN, Cl. (1985). Entre lo uno y lo diverso. Barcelona: Crítica.

HERZBERGER, D. K. (2011). A companion to Javier Marías. Woodbridge, Suffolk: Tamesis Book. JAKOBSON, R. (1981). Lingüística, poética, tiempo (conversaciones con Krystina Pomorska).

Barcelona: Crítica.

JIMÉNEZ PASCUAL, R. (2011). “Vértigo, poesía y credo del cine de Alfred Hitchcock". Foro de Educación 13, 189-204.

KERMODE, F. (1983) [1966-1967]. El sentido de un final. Estudios sobre la teoría de la ficción. Barcelona: Gedisa.

LOTMAN, Y. (1978) [1970]. Estructura del texto artístico. Madrid: Itsmo.

MARÍAS, J. (1995). Vida del fantasma. Madrid: Alfaguara. (2005). Donde todo ha sucedido. Al salir del cine. Barcelona: Galaxia Gutenberg. (2014). Así empieza lo malo. Madrid: Alfaguara.

MARTíNEZ-VASSEUR, P. (2004). “La España de los años 80 en el cine de Pedro Almodóvar". En La historia a través del cine. Transición y consolidación democrática en España, R. Ruzafa Ortega (ed.), 167-202. Bilbao: Servicio Editorial de la Universidad del País Vasco. 
REESCRIBIR EL VÉRTIGO (DE ENTRE LOS VIVOS): LA IMPRONTA CINEMATOGRÁFICA DE HITCHCOCK EN ASÍ EMPEIZA LO MALO, DE JAVIER MARÍAS

MORALES PECO, M. (2011). “El doble exterior como vía de recuperación de la amada muerta en Bruges-la-Morte de Rodenbach, Sueurs froides: D'entre les morts de Boileau y Narcejac, y Vértigo de Hitchcock". Çedill., Revista de estudios franceses 2, 49-82.

PÉREZ BOWIE, J. A. (2010). "Sobre reescritura y nociones conexas. Un estado de la cuestión".

En Reescrituras filmicas: nuevos territorios de la adaptación, J. A. Pérez Bowie (ed.), 21-43. Salamanca: Ediciones Universidad de Salamanca.

PIÑERA TARQUE, I. (2009). Mundos narrativos. Relato literario y relato filmico. Kassel: Reichenberger.

PONCE, F. (2014). "San Francisco. Materia y espíritu". En Ciudades de cine, F. García Gómez y G.

M. Pavés (coords.), 331-347. Madrid: Cátedra.

ROMAN, R. J. (2007). “Javier Marías, cuando el fantasma hace literatura”. Revista de Artes y

Humanidades 20, 154-162.

SANABRIA, Carolina (2011). Contemplación de lo íntimo: lo audiovisual en la cultura contemporánea. Madrid: Biblioteca Nueva.

(2013). Las adaptaciones subliminares. Tres obras maestras de Alfred Hitchcock. Madrid: JC. SPOTO, D. (2001). Alfred Hitchcock: la cara oculta del genio. Madrid: T\&B.

STAM, R.; BURGOYNE, R. y FLITTERMAN-LEWIS, S. (1999) [1992]. Nuevos conceptos de teoría del cine. Barcelona: Paidós.

STEENMEIJER, M. (2001). El pensamiento literario de Javier Marías. Amsterdam-Nueva York: Rodopi.

STOICHITA, V. (2006). Simulacros. El efecto Pigmalión: de Ovidio a Hitchcock. Madrid: Siruela. TRÍAS, E. (1982). Lo bello y lo siniestro. Barcelona: Seix Barral. (1998) [1997]. Vértigo y pasión. Un ensayo sobre la película Vértigo de Alfred Hitchcock. Madrid:Taurus.

TRUFFAUT, Fr. (1974). El cine según Hitchcock. Madrid: Alianza.

WOOD, R. (1968). El cine de Hitchcock. México: Era.

\section{FILMOGRAFÍA}

Vértigo (De entre los muertos), Dir. Alfred Hitchcock. Act. James Stewart, Kim Novak, Henry Jones. 1958. Paramount Pictures.

Recibido el 11 de enero de 2016.

Aceptado el 1 de noviembre de 2016. 
